\title{
Teknokultura
}

ISSNe: $1549-2230$

http://dx.doi.org/10.5209/TEKN.59544

\section{Análise do merchandising social e gênero no discurso transmídia do tráfico de pessoas em Salve Jorge}

\author{
Denise Avancini Alves ${ }^{1}$; Maria Helena Weber ${ }^{2}$
}

Recibido: 17 de marzo de 2018 / Revisado: 24 de agosto de 2018 / Aceptado: 5 de septiembre de 2018 Open peer reviews

Resumo: $\mathrm{O}$ artigo analisa a abordagem do tráfico de pessoas em espaços de entretenimento da televisão brasileira, especificamente, na telenovela Salve Jorge (exibida pela Rede Globo entre outubro/2012 e maio/2013) e em sua extensão transmidiática. A inclusão de temas sociais nas tramas das telenovelas é reconhecida como merchandising social e, ao dramatizá-los, os coloca num espaço privilegiado de visibilidade e de audiência. Para além de dar luz ao tema de interesse público, a narrativa da telenovela tipifica o gênero feminino na lógica do tráfico de pessoas para fins de exploração sexual. O estudo analisa a presença do gênero feminino no discurso do tráfico em Salve Jorge. Utiliza como metodologia a pesquisa bibliográfica, a pesquisa documental e a Análise Crítica do Discurso (ACD) de Fairclough (2001), que apresenta a tridimensionalidade analítica de texto, das práticas discursivas e sociais, preocupando-se com as relações de poder no discurso e a análise do contexto. O que se percebe é que há uma evidência do poder da dramaturgia ao tratar temas de interesse público, porém há uma ótica parcial, dirigida e pautada pela lógica do gênero feminino explorado na narrativa própria da ficção. Há um reforço da objetificação da mulher e de sua exploração no tráfico de pessoas de ordem sexual. Ainda que haja uma sinalização possível de outros públicos sociais (como os travestis), a mulher e a mercantilização do seu corpo se destacam nas cenas e na lógica narrativa, tanto na telenovela como nas derivações de peças de comunicação publicizadas na web pela emissora.

Palavras-chave: dramaturgia; exploração sexual; interesse público; Rede Globo; tráfico humano.

\section{[en] Social merchandising and gender analysis on transmedia discourse of human trafficking in Salve Jorge}

\begin{abstract}
The article analyzes the approach of human trafficking in Brazilian television entertainment products, specifically in Salve Jorge (soap opera broadcasted by Globo Network between October/2012 and May/2013) and its transmedia extension. The inclusion of social issues in soap operas' plots is recognized as social merchandising and, as these themes dramatized, it places them in a privileged space of visibility and audience. Besides bringing up the subject of public interest, the soap opera narrative typifies the feminine gender in the logic of the human trafficking for sexual exploitation purposes. The study analyzes the presence of the female gender in the trafficking discourse in Salve Jorge. As methodology, it uses the bibliographic and documentary researches, and Critical Discourse Analysis (ACD) (Fairclough, 2001), which presents the analytical three-dimensionality of text, discursive and social practices, concerned with power relations in discourse and context analysis. The article highlights the power of dramaturgy in dealing with themes of public interest, but there is a partial view, guided by the logic of the female genre explored in the narrative proper of fiction. There is a strengthening of women's objectification and their exploitation in the people trafficking of a sexual
\end{abstract}

\footnotetext{
$1 \quad$ Universidade Federal do Rio Grande do Sul (Brasil)

e-mail: deniseavancinialves@yahoo.com.br

2 Professora Titular na Universidade Federal do Rio Grande do Sul (Brasil)

e-mail: mhelenaweber@terra.com.br
} 
nature. Although there is a possible signaling of other social audiences (such as cross-dressers), women and the mercantilization of their bodies stand out in the scenes and the narrative logic, in the telenovela as well as in the derived communication pieces advertised on the web by the broadcaster.

Keywords: dramaturgy; human trafficking; public interest; sexual exploitation; Rede Globo.

Sumário: 1. Breve panorama do tráfico de pessoas e suas repercussões. 2. A telenovela e sua relevância no Brasil. 3. A telenovela Salve Jorge e o tráfico de pessoas. 4.Salve Jorge e sua extensão transmidiática. 5. Análise crítica do discurso de Salve Jorge e em seus produtos transmidiáticos. 6. Considerações finais. 7. Referências

Cómo citar: Avancini Alves, D. y Weber, M. H. (2018). Análise do merchandising social e gênero no discurso transmídia do tráfico de pessoas em Salve Jorge, en Teknokultura 15(2), 241-257.

\section{Breve panorama do tráfico de pessoas e suas repercussões}

O tráfico de pessoas é considerado uma prática de escravidão moderna, muitas vezes invisível e de difícil rastro aos olhos sociais. Segundo a Organização das Nações Unidas (ONU), quando estabelece em Assembleia Geral o Protocolo de Palermo, indica que o tráfico humano tem como finalidade quatro vertentes, contemplando a exploração humana para a prática do trabalho forçado, a remoção de órgãos, o casamento servil ou, por fim, a exploração sexual, sendo ela exercida pela ação de:

... recrutamento, o transporte, a transferência, o alojamento ou o acolhimento de pessoas" por meio de "ameaça ou ao uso da força ou a outras formas de coação, ao rapto, à fraude, ao engano, ao abuso de autoridade ou à situação de vulnerabilidade ou à entrega ou aceitação de pagamentos ou benefícios para obter o consentimento de uma pessoa que tenha autoridade sobre outra" (Brasil, 2004).

Segundo estimativas econômicas, o tráfico humano movimenta mais de 30 bilhões de dólares por ano e é considerado o terceiro maior negócio em giro de capital no mundo, depois dos tráficos de drogas e armas. No Brasil, o tema entra em pauta pelo Governo Federal em 2004, com a publicação de decretos que promulgam a convenção das Nações Unidas contra o crime organizado transnacional e protocolos adicionais. Desde então, tem sido discutido no âmbito federal com o lançamento de Planos de Enfrentamento ao Tráfico de Pessoas (2008 e 2013), bem como a realização de simpósios para debater o problema de ordem internacional. Segundo mapeamento do Ministério das Relações Exteriores, entre 2005 a 2011, foram localizados 450 casos de vítimas de tráfico de pessoas especificamente para fins de exploração sexual.

Com base em pesquisas da Pestraf (Leal e Leal, 2002), os dados indicam que a maioria dos casos de tráfico de pessoas apuradas no Brasil se configurou por meio de denúncia anônima ou depoimento das vítimas ou parentes, apontando apenas 30,56\% por parte de investigação sob a responsabilidade da Polícia Federal, por flagrante de delito ou requisição do Ministério Público. É um crime de difícil mapeamento e há uma predominância de gênero como vítima. Entre os 36 casos que compõe a amostra, foi encontrado apenas um envolvendo homem. Um dos fatores apontados pelo 
diagnóstico para tal achado é a abordagem do tráfico de forma específica às mulheres, adolescentes e crianças, no tocante a legislação brasileira, demarcando, portanto, uma questão de gênero. Dentre as ocupações verificadas entre as mulheres traficadas estão as de empregada doméstica, cobradora, manicure, vendedora, etc., reforçando um público como uma classe mais carente, em busca por um outro estilo de vida.

Algumas associações com o biopoder podem ser realizadas para entender o tráfico humano:

Na centralidade do tema, está a transformação do corpo (do outro) em mercadoria, onde vítimas do tráfico de pessoas são exploradas para fins do meretrício que, já na condição de condenadas pela sociedade (tendo em vista a prática da prostituição), são alvo de dupla vigilância panóptica na lógica foucaultina, pois sofrem a punição ao suportar também a considerada moderna forma de escravidão imposta pelos aliciadores que, por sua vez, utilizam da justificativa da dívida econômica e da restrição de documentos para subjugá-las (Alves, 2017, p. 273).

Em continuidade, como indicado por Foucault,

O panoptismo é um dos traços característicos da nossa sociedade. É uma forma de poder que se exerce sobre os indivíduos em forma de vigilância individual e contínua, em forma de controle de punição e recompensa e em forma de correção, isto é, de formação e transformação dos indivíduos em função de certas normas. Este tríplice aspecto do panoptismo -vigilância, controle e coerção- parece ser uma dimensão fundamental e característica das relações de poder que existem em nossa sociedade (Foucault, 2002, p.103).

Nesse sentido, a vigilância no tráfico é constante, colocando a aliciada numa situação de refém do próprio ciclo de abuso pelo crime estabelecido, ora por pagar a dívida acumulada, ora pela condenação social implícita na exploração sofrida.

Dando continuidade à apropriação do tema em outras esferas, no que se refere à sociedade civil e religiosa, entre 2013 e 2014, o tráfico de pessoas também foi pauta na mídia brasileira com maior ênfase por intermédio de campanhas de sensibilização e de engajamento, tanto de ordem não governamental (Campanha do Coração Azul) como de ordem religiosa, com o lançamento da Campanha da Fraternidade de 2014, pela Conferência Nacional dos Bispos do Brasil (CNBB).

No âmbito de produtos de entretenimento televisivos no Brasil, o tema do Tráfico de pessoas foi o elemento central abordado na telenovela Salve Jorge, de Gloria Perez, exibida pela Rede Globo entre 22 de outubro de 2012 e 17 de maio de 2013 (e posteriormente veiculada em outros países). A inserção de temas de interesse público no entretenimento, em especial, nas telenovelas brasileiras, tem sido um recurso utilizado por seus autores, observando a amplitude de audiência e sua repercussão em outros programas televisivos, bem como seu fator influenciador no campo de políticas públicas brasileiras e, sequencialmente, para a projeção de imagem da emissora.

A prática da inclusão de tais temas nas tramas das telenovelas é reconhecida ou denominada de merchandising social. Portanto, é neste espaço midiático privilegiado de ficção que também se constitui a narrativa de um problema social, sendo, 
a telenovela, "um objeto que causa estranhamento devido a sua extrema simplicidade (aparência) e complexidade (compreensão)" (Weber e Souza, 2009, p. 142).

Com base nesse contexto, o presente estudo objetiva analisar o discurso transmídia do tráfico em Salve Jorge, especialmente a exploração mercadológica do corpo feminino para fins sexuais, considerando a projeção de visibilidade e de debate do tema. Na telenovela, é possível tratar visualmente (e garantir audiência) a estética feminina e o uso do seu corpo como produto, que também é reflexo do imperativo comercial que o gênero feminino recebe na dimensão do tráfico de pessoas na vida real e criminal.

\section{A telenovela e sua relevância no Brasil}

A telenovela é um produto cultural que edita, condiciona e auxilia a projetar cultura de um país. Martín-Barbero (2003) reforça que o melodrama, na vida cotidiana, sedimenta um terreno de formação de identidades. O autor indica a importância do melodrama na América Latina, que se estrutura com base na identificação que as classes populares mantêm com sua narrativa. A televisão ocupa "nas dinâmicas da cultura cotidiana das maiorias, na transformação das sensibilidades, nos modos de construir imaginários e identidades" (Martín-Barbero, 2003, p. 26). Há uma produção de estilização, de reconstrução e correspondência dos traços físicos e aparência dos personagens. Essa codificação deve promover sentido na audiência. Em especial no Brasil, as telenovelas reinventam e atualizam o próprio gênero, permitindo uma maior identificação com o público. "Durante cerca de vinte anos a novela se manteve nessa posição, afirmando características estilísticas e um modo de fazer que ficou conhecido como 'brasileiro', e que mobiliza públicos nacionais" (Hamburguer, 2005, p. 68).

A forma capitular do produto, apresentando seu próprio tempo e edição, faz com que o espectador mantenha um contínuo interesse. Essa serialidade é uma das características fundamentais da telenovela. A trama é apresentada ao telespectador em capítulos diários como "uma única narrativa (ou várias narrativas entrelaçadas e paralelas) que se sucede $(\mathrm{m})$ mais ou menos linearmente ao longo de todos os capítulos" (Machado, 2001, p. 84). Tal característica é considerada facilitadora na medida em que estabelece uma rotina que concorre ou ocorre, com e/ou simultaneamente as demais atividades da vida doméstica e permite que o telespectador acompanhe a sequência do enredo diariamente. Além dessa característica, com o apoio digital, a audiência pode acompanhar a trama pela internet, acessando a reprodução de capítulos disponíveis em sites abertos ou por assinaturas, editando a lógica de acesso à narrativa, mas mantendo o interesse pelo produto, mesmo que em outra plataforma.

Assim, ao aproximar os limites da ficção com a realidade, foi se constituindo com o que Lopes (2003) designa como um recurso comunicativo, trazendo para a trama um repertório de elementos estéticos e de linguagem reconhecidos e compartilhados pelos brasileiros. Ao utilizar a estratégia de retratar preocupações sociais contemporâneas em suas tramas, a telenovela consegue promover ou instigar discussões. "[...] A novela passou a ser um dos mais importantes e amplos espaços de problematização do Brasil, indo da intimidade privada aos problemas sociais" (Lopes, 2009, p. 26).

Esta tentativa de narrar, (re)interpretar ou reproduzir discussões da sociedade atual é potencializada pelo que se denomina de merchandising social que, ao transpor a (re)leitura do real para a ficção, traz elementos que dão suporte à manutenção 
de uma estética que é capaz de reunir os aspectos de um melodrama. Situações de violência, pobreza, crimes, tráfico, prostituição, drogas, abusos, esquizofrenia são temas duros que o melodrama incorpora, dá voz e corpo, assumindo sua característica estética e redoma ficcional, podendo suavizar ou intensificar seu apelo conforme o grau de aceitação da recepção.

Soma-se a esse olhar o poder de sedução da mídia, pois:

... as mídias, com lógica e poder equivalentes aos do Estado e do capital, destes se diferenciam pela agilidade, perspicácia e ingênua e transparente capacidade de sedução. Podem relativizar o real - a história -, mostrando-o de uma perspectiva menos inóspita, mais confortável, fornecendo álibis ao cidadão sobre a impossibilidade de mudar, pela complexidade do poder e da política (Weber, 2000, p. 121).

Neste contexto, tem-se a telenovela Salve Jorge, produzida pela Rede Globo, que utiliza o merchandising social como base para a construção da trama. Dentre os temas tratados, estão a alienação parental e tráfico internacional de bebês, mas de forma mais densa e permanente, o tráfico para fins de exploração sexual é nuclear durante todo o percurso da telenovela.

\section{A telenovela Salve Jorge e o tráfico de pessoas}

Escrita por Glória Perez -autora de telenovela no Brasil com reconhecimento e projeção internacional, tem como marca autoral dar luz e voz a temas sociais-, Salve Jorge estreou às $21 \mathrm{~h}$ na TV Globo, no dia 22 de outubro de 2012, encerrando sua exibição em 17 de maio de 2013 (reprise do último capítulo no dia 18 de maio). Com 179 capítulos, a média de audiência da telenovela foi de 33,6 pontos, o que, segundo o Instituto Brasileiro de Opinião Pública e Estatística, corresponde a 33,6\% dos televisores brasileiros acompanhando a telenovela. Os capítulos, veiculados de segunda a sábado, apresentavam uma média de 75 minutos de duração. A telenovela foi exportada para diversos países, dentre eles Portugal e países africanos, onde a Rede Globo já apresenta parcerias de veiculação de seus produtos de entretenimento.

O elenco contou com 91 personagens, além de figurantes. Os espaços geográficos prioritários da trama se localizavam no Rio de Janeiro (Brasil), em especial, no Complexo do Alemão, local de origem da protagonista. Em âmbito internacional, na Turquia, mesclando cenas da Capadócia e de Istambul.

O tema tráfico de pessoas é o cerne social do enredo, abrindo o primeiro capítulo da novela com uma projeção temporal de 8 meses, retratando cenas de um leilão da protagonista na Turquia (país-cenário onde a exploração sexual é praticada). As vítimas do tráfico para fins de exploração sexual são chantageadas por uma quadrilha com a "justificativa" de dívida adquirida pela viagem, ameaça familiar e restrição de acesso aos documentos, configurando-as como imigrantes ilegais naquele país.

A cena do leilão é filmada no interior de uma mansão, numa sala, e ao centro, numa espécie de tablado, está a personagem traficada, Morena (Nanda Costa) que vive no Morro do Alemão (comunidade dominada pelo tráfico de drogas), compõe o núcleo central da trama. No episódio de estreia, ela se apresenta bem maquiada, vestida com adereços elegantes e com roupa sensual. Ao redor, homens de diversas 
nacionalidades (idiomas sobrepostos fazem a vez do off da cena), vestindo ternos, fumando charuto, bebendo e conversando, admirando o produto que ela representa. A objetificação da mulher é percebida de forma plena, além da naturalidade da ação, configurando-se como uma prática já estabelecida. Há uma estética visual de um ambiente de alto nível econômico, o que não necessariamente representa as transações habituais como o crime mundialmente é praticado. Associa-se aqui o olhar de Baudrillard (2014), que nos indica que o corpo e o erotismo são materializados como objetos de consumo, contribuindo de forma explícita na venda de produto, no caso, o próprio corpo.

Em continuidade à cena, um homem interessado se levanta e vai tocar e cheirar a jovem. Esse mesmo homem faz a proposta e sai com a traficada vendida que, por sua vez, apresenta repulsa e angústia na cena. A mercadoria se estabelece. Logo após, entra mais uma jovem, configurando a circulação das transações, com mulheres objetificadas como produtos na prateleira numa linha produtiva. A mulher, portanto, é objetificada e atrai os olhares masculinos da plateia e, como Baudrillard (2014, p. 116) indica, os valores ditos como naturais de encanto, beleza e sensualidade são substituídos pela potencialidade do erotismo e de sofisticação. Tais cenas podem ser observadas na Figura 1.

Figura 1. Frames do primeiro capítulo da novela Salve Jorge. Fonte: GShow
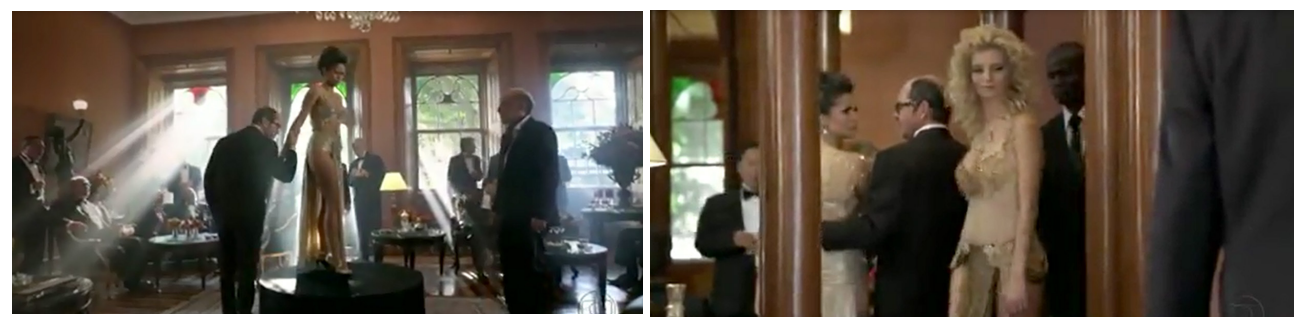

Os quatro minutos iniciais de Salve Jorge são destinados a apresentar a localização de onde passará a trama, tendo como ponto alto o leilão de uma traficada. Algumas características são explicitadas pelo leiloeiro, dentre elas a maioridade e o fato da traficada ser brasileira. Tais informações reforçam ou podem ser associadas à pseudogarantia da legalidade da atividade (pela maioridade) bem como a característica da nacionalidade (brasileira), considerada um atributo pela visibilidade da mulher latina em âmbito internacional.

A partir de então, a novela volta no tempo em 8 meses, um regresso temporal que (re)situa o espectador. Na construção da trama o que se vê de fato são os contextos já estabelecidos na composição do produto dramatúrgico. Em Salve Jorge, a fórmula não se altera. As subtramas se apresentam, trazendo as relações amorosas, os desafetos, a sexualidade prevista na ação do tráfico e na sedução, as diferentes dimensões de classe social, as discussões e conflitos familiares, a bondade, as ações públicas nas esferas do Exército e da Polícia Federal, e a vitória do bem contra o mal ou o sentimento de justiça realizado como suposto final feliz. Assim, a trama de Salve Jorge pode ser então detalhada.

Morena, a heroína da trama, moradora do Complexo do Alemão (RJ) se mostra uma mulher independente, que foi mãe muito jovem e ao ser abandonada pelo pai do filho, criou o menino sozinha, com a ajuda da mãe. Na vida amorosa seu par român- 
tico é o capitão do Exército Théo (Rodrigo Lombardi), responsável pela pacificação e instalação das UPPs (Unidades de Polícia Pacificadora) na favela. O casal enfrenta obstáculos ao longo da trama para viver sua história de amor, próprio do produto melodramático. Desiludida com a relação com Théo, correndo o risco de perder a casa por questões econômicas e em busca de melhores condições e oportunidades para a sua família, Morena viaja para a Turquia por convite de Wanda (Totia Meireles), que a engana fazendo acreditar que ela trabalhará como garçonete quando na realidade terá de vender seu corpo, junto a outras mulheres estrangeiras, em uma boate que funciona secretamente como casa de prostituição. Assim, têm início a saga de Morena como traficada.

A sequência de fatos demonstra o crime do tráfico de pessoas para exploração sexual: o perfil das vítimas (mulheres jovens, com dificuldades financeiras), a persuasão emocional dos aliciadores ao tecerem promessas de um futuro promissor e o encarceramento numa boate ou local fechado, sem contato com o ambiente externo ou possibilidade de falar com os parentes, que, nesse momento, já podem se considerar vítimas, pois são coagidas sempre, além de agressões físicas e psicológicas pela quadrilha.

Nesse contexto, outra linha reflexiva se dá na leitura da interseccionalidade indicada por Crenshaw, que busca conceituar o problema na captura "das consequências estruturais e dinâmicas da interação entre dois ou mais eixos da subordinação" (2002, p.177). No presente estudo, tais eixos podem ser tratados como o gênero e a vulnerabilidade social dessas vítimas, potencializando sua fragilidade. Soma-se o fato de que a "interseccionalidade trata da forma como ações e políticas específicas geram opressões que fluem ao longo de tais eixos, constituindo aspectos dinâmicos ou ativos do desempoderamento" (Crenshaw, 2002, p.177).

As principais vítimas são as mulheres em situação de fragilidade (econômica ou social) que são enganadas e exploradas para o tráfico de pessoas para fins sexuais. Além de Morena, na Turquia, Jéssica (Carolina Dieckman) e Waleska (Larissa Dias) são outras aliciadas. Jéssica é carioca e foi levada para Espanha com a promessa de ser atendente em uma pizzaria, mas acabou em uma boate de prostituição. Indignada, Jéssica sempre lutou para fugir. Sua personagem protagonizou uma cena (Figura 2) de um suposto estupro do gerente da boate (Russo), veiculado no final do capítulo de 3/11/2012 e no início do dia 5/11/ 2012.

A história de Jéssica foi inspirada na vida de Simone Borges, vítima do tráfico e morta na Espanha em 1996. Com Morena, Jéssica tentou escapar e foi obrigada a servir de mula de droga. No Brasil, descobriu quem era a líder da quadrilha e acabou morta.

Figura 2. Cenas que remetem ao estupro de Jéssica. Fonte: GShow
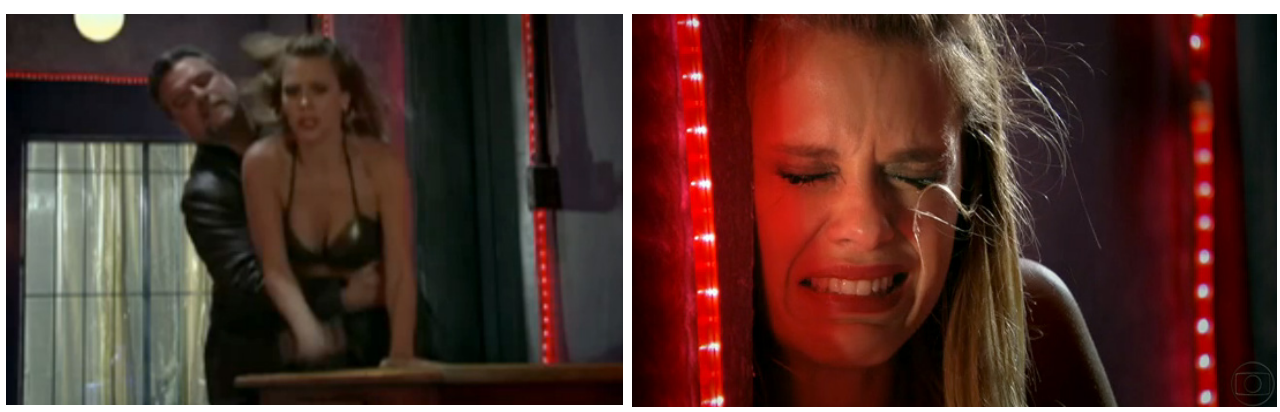
Waleska, outra vítima do tráfico, é uma jovem que já trabalhava como garota de programa no Brasil. Aceitou uma oferta de Wanda, mas acabou sendo escravizada, com a restrição aos documentos. Com personalidade forte e conhecendo a estratégia do lugar, luta para pagar sua dívida e se soma com Morena, de quem recebe um celular e passa a ser informante da polícia federal, que consegue mapear o esquema do tráfico de pessoas, ao menos na ficção.

A inserção de fatos reais (Figura 3), como o depoimento da empregada doméstica Ana Lúcia Furtado, traficada para Israel em 1998 à delegada de polícia é um recurso usado em Salve Jorge. Há uma tentativa de aproximação com a realidade, com o uso de testemunhais fracionados que buscam credenciar a trama. A traficada na vida real era empregada doméstica e sustentava três filhos quando, aos 24 anos, recebeu uma proposta para o que sonhava ser um futuro melhor: trabalhar como garçonete em Israel. Acabou virando prostituta numa boate e serviu de inspiração para a autora Glória Perez moldar a personagem da protagonista Morena. O depoimento, na ficção, ocorreu após o capítulo 85 , exibido em 28/01/2013.

Figura 3. Frame do depoimento de Ana Lúcia Furtado à delegada na novela. Fonte: GShow

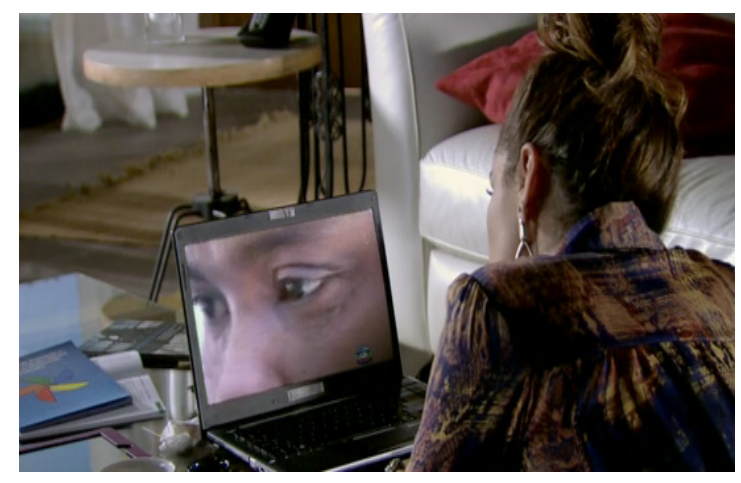

Ana Lúcia relata como foram os três meses que ficou em poder da quadrilha e a morte de sua prima, Kelly Martins, com quem viajou para Israel e inspiradora da personagem Jéssica. Em sua fala é possível observar a descrição de como ocorreu o aliciamento:

Eu estava no pagode Madureira, eu e minha amiga Kelly, quando conhecemos a Rosana... ela se aproximou, criou um círculo de amizade com a gente, quando depois, no final da noite, ela nos fez a proposta pra viajar pra fora do país, pra trabalhar como garçonete numa lanchonete em Israel. Nesse meio tempo, ela criou um círculo de amizade conosco, frequentou a nossa casa,conheceu a nossa família, se tornou a nossa amiga (Entrevista em G1, Globo, 2013).

Mesmo com a diferença do tratamento estético entre a ficção e realidade percebida na trama, os afetos, as paixões e a sexualidade são elementos continuamente expostos na tela. Há uma apropriação de elementos próprios da telenovela que projetam sua universalidade, o que não ocorre na vida real. Há uma imitação da vida ao trazer esses testemunhos e inspirações para dentro da narrativa, mas a novela se coloca destoante da própria fonte e convida o público para sua 
encenação. Sob a ótica de Bourdieu, há um 'esquema' "para ver e avaliar os dominantes (elevado/baixo, masculino/feminino, branco/negro etc.), resultam da incorporação de classificações, assim naturalizadas, de que seu ser social é produto" (Bourdieu, 2012, p. 47). Talvez, essa classificação de dominação só se manifeste na vida real, onde os dominados raramente apresentam final feliz. Salve Jorge mescla efeitos de realidade para essas situações, que foram vivenciadas pela comunidade do Rio de Janeiro na vida real, e na tela, foram romantizadas e pacificadas.

\section{Salve Jorge e sua extensão transmidiática}

Além da veiculação da novela pela televisão, a Rede Globo investe em produção de conteúdo para a web, considerando a "penetração e o crescimento sustentado da internet na Ibero-América e o acelerado uso das redes sociais virtuais na região, especialmente o Facebook e o Twitter" (Lopes e Gomez Orozco, 2014, p. 55). Segundo dados do OBITEL,

... entre os usuários de ficção, $82 \%$ mostraram-se ativos em suas visitas às plataformas selecionadas, sendo suas principais ações comentar, criticar e discutir, com os produtores e com outros usuários, os conteúdos do produto ficcional, isso tomando como referência a participação dentro dos sites oficiais (Lopes e Gomez Orozco, 2014, p. 61).

Acompanhando essa tendência, a emissora, além dos capítulos disponíveis para assinantes do portal G1, ofereceu conteúdo exclusivo em seu site, disponibilizado, em ambiente digital, materiais complementares à trama, ampliando a oferta do tema e extrapolando o horário televisivo, sendo essa estratégia considerada uma extensão transmídia. Salienta-se que, para apresentar uma narrativa transmidiática:

... é necessário que haja uma expansão do universo ficcional em diferentes plataformas, sendo fundamental que cada um dos conteúdos dispersos seja autônomo e independente entre si. Na forma ideal de narrativa transmidiática, cada meio faz o que faz de melhor [...]; seu universo possa ser explorado em games, ou experimentado como atração de um parque de diversão". Já, crossmídia refere-se ao "cruzamento de diversos meios com a mesma narrativa, portanto sem autonomia de conteúdo em cada plataforma" (Jacks et al. 2013, p. 182).

Fechine et al (2013) reforça a ideia da possibilidade da emissora disponibilizar "conteúdos repropostos ou reempacotados" (p. 29), em plataformas complementares aos próprios produtos televisivos. Nesse sentido, em Salve Jorge, diversos materiais foram produzidos. Dentre os observados, destaca-se a composição de uma história em quadrinhos (HQ) elaborada com o percurso de uma personagem que não apresentou um final feliz tradicionalmente esperado no me- 
lodrama. Trata-se da traficada Jéssica que desempenhou um papel relevante para a discussão sobre o tema tráfico de pessoas, mas sua história não teve sequência até o final da trama, sendo assassinada ao longo da veiculação de Salve Jorge. Para manter viva na memória a personagem e ampliando as possibilidades de dinâmicas de interação com a ficção, a Rede Globo publicou no site da novela a história estilizada num formato HQ (Figura 4), contendo os seguintes título e linha de apoio: "O Drama de Jéssica: reveja a história da traficada em quadrinhos" (Gshow, Globo, 2013).

Figura 4. HQ: O Drama de Jéssica. Fonte: Rede Globo
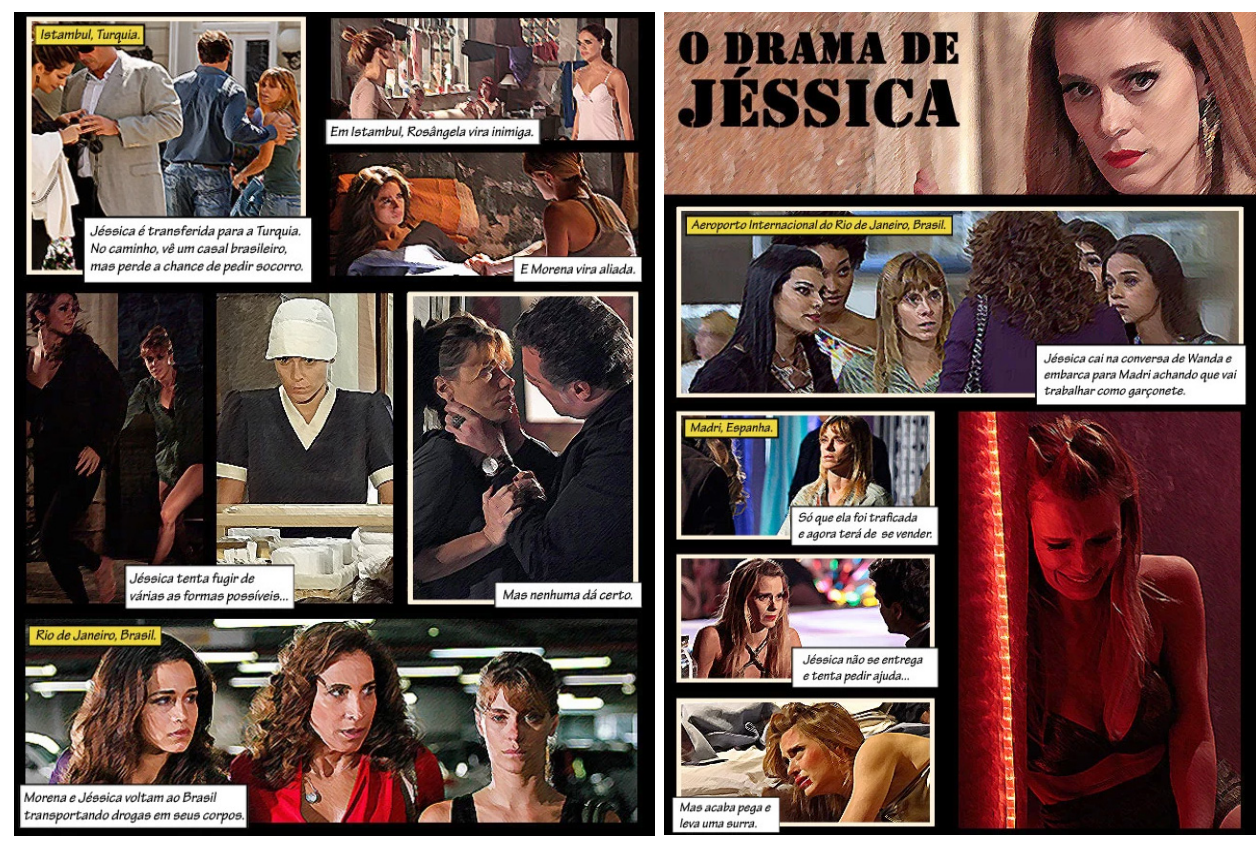

O investimento em conteúdos mais visuais tende a contribuir para que as informações possam ser assimiladas mais facilmente pelos internautas. Ao emprestar uma nova forma de tradução do texto narrativo em HQ, pode transformar a personagem Jéssica em uma super-heroína, comumente observado em produções desse gênero. Além disso, em HQs com super-heróis tem-se o recurso de um disfarce para ocultar a identidade do protagonista. Nesse caso, o disfarce é o próprio silêncio do crime.

Outro conteúdo oferecido de forma transmídia, encontra-se no Dossiê do Tráfico (Figura 5) produzido pela Rede Globo, que se refere a um material disponibilizado no site da novela que resume o que seria a documentação dos personagens envolvidos na trama pelo tráfico de pessoas, com a produção do conteúdo em três categorias de vínculo: traficadas, traficantes e vítimas. O site apresenta um resumo sobre o perfil de cada personagem envolvido no tráfico, bem como complementa o conteúdo com fotografias e vídeos, simulando um conjunto de arquivos que reúne informações sobre as traficadas, os traficantes e as vítimas da operação retratada na novela. 
Figura 5. Dossiê do Tráfico. Fonte: Rede Globo
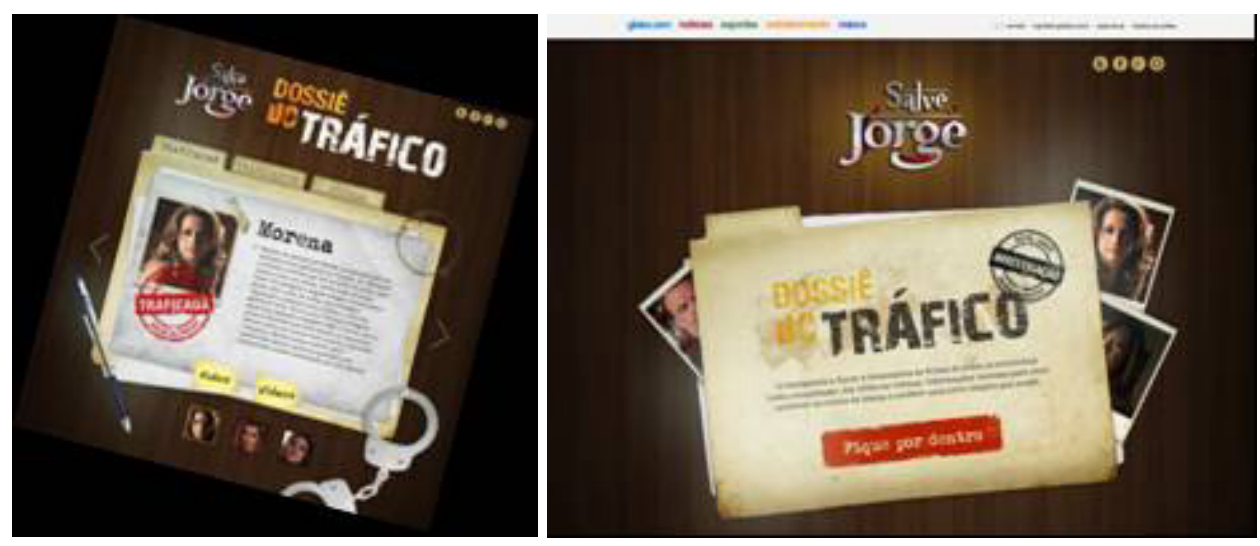

A estrutura do dossiê faz alusão a uma estética visual de relatório policial, com ficha técnica dos personagens, símbolos e ícones que remetem a elementos acionados pela esfera legal, como carimbos e algemas. Há um empréstimo da ficção para outras plataformas para além da reprodução dos capítulos. O site oferece conteúdo complementar, tanto no dossiê, como na história em quadrinhos, num formato de apropriação de linguagem visual que dá sinais de realidade presente no imaginário da audiência.

Com base na dramatização do tráfico de pessoas observada em Salve Jorge, é possível corroborar que a Rede Globo, nas suas diversas derivações do melodrama, se torna um elemento importante na construção de significações do tema junto à sociedade, sendo responsável por dar luz e voz ao tráfico de pessoas, promovendo a sua manutenção temática conforme o seu interesse mercadológico e reconstruindo e reconfigurando identidades sociais. Outros estudos indicaram o efeito positivo do merchandising social em Salve Jorge, correlacionando a exibição das cenas de tráfico de pessoas na trama com a frequência de notícias publicadas e de denúncias registradas (Vale, 2016).

Por outro lado, há um distanciamento visual e narrativo que descola da realidade, romantizando o tráfico e promovendo uma maquiagem na densidade do problema. A identidade de gênero é reforçada na novela, que tem como todas as aliciadas no dossiê, mulheres bonitas, conhecidas atrizes pela sociedade brasileira, que emprestam sua estética para histórias duras, densas e criminais, o que, de certa forma, suavizam do tema considerando a narrativa visual do produto melodramático.

\section{Análise crítica do discurso de Salve Jorge e em seus produtos transmidiáticos}

Utiliza-se como referência a perspectiva de Fairclough (2001), que nomina Análise Crítica do Discurso (ACD) uma abordagem da Teoria Social do Discurso, entendendo o evento discursivo na tridimensionalidade: texto, prática discursiva e prática social. Ao incorporar a ACD para o presente estudo, localiza-se na telenovela e suas derivações transmidiáticas um produto cujo discurso é híbrido por natureza. Ela apresenta uma mistura de sons, imagens e amplitude de abordagens em outros 
produtos midiáticos. Desse modo, o gênero televisivo utiliza um discurso heterogêneo, dialógico e também ideológico, que indica uma possibilidade de agir como transformador social, nesse caso, tendo como elemento central o debate do tráfico de pessoas.

No contexto de análise de trazer luz ao tema através de um produto melodramático, o paradoxo da visibilidade se manifesta, pois ao mesmo tempo em que a novela auxilia na divulgação do tráfico de pessoas, o transforma numa leitura de HQ ou na lógica de um dossiê policita, e ao romantizá-lo, pode diminuir seu impacto como problema social, até mesmo neutralizá-lo, transformando-o em um produto editado e editável. O tema é levantado, linearizado em cenas, o bem se sobrepõe ao mal, mas não encerra a discussão do problema social.

Como elementos de discussão, percebe-se a mercantilização do tema, pois a vitalidade ou a manutenção do debate são dependentes dos investimentos mercadológicos e dramatúrgicos, para além da análise da relevância como problema público. Nas relações sociais estabelecidas no enredo da telenovela, ao mesmo tempo em que há uma apresentação do tráfico de pessoas na trama, o próprio produto televisivo exporta a cultura e características brasileiras, como sensualidade e culto ao corpo, ampliando o olhar do aliciador para o país, associado aos fatores econômicos que potencializam o discurso de oportunidade para as aliciadas.

Fairglough (2001, p.106) indica que a prática discursiva "envolve processos de produção, distribuição e consumo textual, e a natureza desses processos varia entre diferentes tipos de discurso de acordo com fatores sociais", oferecendo uma amplitude de variação analítica, tanto de ordem de produção como de consumo. A centralidade do tráfico de pessoas é manifestada como trama principal da novela, apresentado já como fator desencadeador, sendo desmembrado em núcleos principal e paralelos de atuação e nas suas relações decorrentes.

É possível analisar as metáforas textuais, nesse caso, representadas nas imagens e na serialidade próprios da telenovela. Na sociedade contemporânea, a conversação surge no diálogo com a própria trama e por intermédio das informações de transmídia da emissora. Essa relação dialógica pode ser observada na mescla de elementos de realidade na ficção.

Em Salve Jorge o drama do tráfico de pessoas se estabelece, ganhando voz e imagem ao esquema do crime. Na ficção, a construção da identidade social é assumida pelos estereótipos dos personagens, trazendo elementos de representação coletiva. A traficada assume essa dimensão de protagonista, sendo uma aliada à proposta de uma narrativa convincente à audiência, "leitora" do texto produzido pela telenovela. Os depoimentos de vida também compõem essa textualidade, conferindo elementos de realidade à narrativa.

Conforme observado na tese de Alves (2015), na dimensão texto da telenovela, os bordões são elementos presentes, especialmente quando for de autoria de Glória Perez. Em Salve Jorge, o folhetim esbanjou termos turcos, além dos visuais como dança típica, cenário da Capadócia foram continuamente lembrados durante a exibição, (re)situando o telespectador em termos geográficos. Conforme indica Fairclough (2001, p. 100) "devemos tentar compreender como os membros das comunidades sociais produzem seus mundos 'ordenados' ou 'explicáveis"'. A ficção empresta um vocabulário próprio do gênero, sendo possível situar os núcleos dramáticos e até mesmo reduzir o elemento naturalmente pesaroso que o tráfico de pessoas tem em nome do produto melodramático. 
Soma-se ao texto o olhar da estética dos personagens e de seus cenários. As aliciadas confinadas num ambiente que reproduz o cenário de boate e de moradia-cárcere, utilizando roupas que remetem à exploração sexual e sua função como mercadoria. Em continuidade, tem-se o Morro do Alemão, com a simplicidade das instalações e diálogos com fala alta e uso de gírias, e assim tantos outros elementos que podem ser analisados, próprios da composição de telenovela.

No que se refere ao gênero, Fairclough (2001, p. 252) afirma que há uma assimetria entre homens e mulheres, sendo que a literatura vem observando a existência de redução das atividades ou características consideradas femininas em detrimento daquelas estabelecidas como masculinas. Fairclough (2001, p. 253-254) indica que profissões ou atividades exemplificadas na literatura como 'secretárias' ou 'enfermeiras' são sempre indicadas pelo gênero feminino, enquanto que atividades percebidas como mais nobres ou intelectuais, como 'aluno' ou 'orientador', são consideradas com o estereótipo masculino. No presente estudo, essa assimetria é um elemento que une todos os espaços de circulação, pois a mulher é que é retratada ou representada no papel de aliciada. Além disso, em termos de audiência, a telenovela é uma narrativa endereçada especialmente para as mulheres, reforçando a dimensão estratégica da emissora ao protagonizar o gênero de forma heroica. Portanto, o tráfico de pessoas tem, prioritariamente, na mulher a localização da vítima.

Por outro lado, tal contexto reforça a lógica da leitura social da posição dessas mulheres, que na ótica da interseccionalidade de Crenshaw (2002) reforça o esteriótipo das aliciadas, que tornam-se "especialmente vulneráveis a medidas punitivas, baseadas em como suas identidades são percebidas pelos outros" (p.179).

Quanto à prática discursiva, a intertextualidade está presente em Salve Jorge tanto no âmbito da construção de sua narrativa, quanto na esfera dos valores socioculturais subjacentes em discursos contidos em sua trama. Weber (2000) indica sobre a estética da televisão, dando maior ênfase aos discursos mais facilmente assimiláveis. O tema dramatizado tende a ser melhor interpretado e aceito pelo público ao comparado com aquele abordado de forma dura pela legislação. A novela empresta a suavidade e a estética visual ao tema sombrio do tráfico de pessoas. O merchandising social, portanto, é uma estratégia que constitui a prática discursiva, contextualizando a problemática social internacional do tráfico humano, além de trazer os elementos da pacificação do morro do alemão, a fragilidade da representação policial e os problemas que surgem na ausência de uma liderança da força militar.

Em termos de produção e distribuição, a telenovela tem uma penetração elevada, com consumo coletivo e diário, além de contar com elementos transmidiáticos para compor o acesso ao tema e à própria trama (via reprises dos capítulos no portal ou aplicativos). No que se refere aos conteúdos como na História em Quadrinhos e no Dossiê do Tráfico, há uma coerência e intertextualidade, trazendo elementos da novela para outras plataformas e formatos, além de promover a localização dos personagens nos seus núcleos narrativos, oferecendo à audiência uma complementação de conteúdo. A busca do conteúdo é via web, com distribuição simples e ativada pelo internauta. De forma específica, é possível realizar a análise tridimensional nos produtos transmidiáticos, conforme o quadro 1 . 
Quadro 1. ACD dos produtos digitais de Salve Jorge. Fonte: das autoras

\begin{tabular}{|c|c|c|}
\hline $\mathrm{ACD}$ & HQ & Dossiê do Tráfico \\
\hline $\begin{array}{l}\text { Texto } \\
\text { Vocabulário, } \\
\text { Gramática, } \\
\text { Coesão, Estrutura } \\
\text { textual }\end{array}$ & $\begin{array}{l}\text { Inovação no formato (arquitetura do } \\
\text { texto); recursos visuais, onde há uma } \\
\text { apresentação da situação geográfica } \\
\text { (fundo amarelo) e descrição da cena } \\
\text { (fundo branco), quando a história é } \\
\text { narrada por terceiros. }\end{array}$ & $\begin{array}{l}\text { Estética visual associada à de um relatório } \\
\text { policial imagético, com símbolos e ícones } \\
\text { presentes na dimensão policial. }\end{array}$ \\
\hline $\begin{array}{l}\text { Práticas } \\
\text { discursivas } \\
\text { Produção, } \\
\text { Distribuição, } \\
\text { Consumo, } \\
\text { Contexto, Força, } \\
\text { Coerência, } \\
\text { Intertextualidade }\end{array}$ & $\begin{array}{l}\text { Conteúdo via web, com distribuição } \\
\text { simples, porém com necessidade } \\
\text { de ativação pelo internauta. Há o } \\
\text { protagonismo paralelo e a rotina de } \\
\text { produção se dá de forma única, sem } \\
\text { a serialidade característica da novela. }\end{array}$ & $\begin{array}{l}\text { Coerência, no contexto do 'fichamento' } \\
\text { dos personagens que promove a } \\
\text { localização deles nos seus núcleos } \\
\text { narrativos, oferecendo à audiência uma } \\
\text { complementação de conteúdo. A busca } \\
\text { do conteúdo é via web, com distribuição } \\
\text { simples e ativada pelo internauta. } \\
\text { Protagonismo reforçado, além de } \\
\text { uma rotina de produção única e de } \\
\text { reprodução, pois há um aproveitamento } \\
\text { de vídeos veiculados na TV. }\end{array}$ \\
\hline $\begin{array}{l}\text { Prática Social } \\
\text { Sentidos, } \\
\text { Pressuposições, } \\
\text { Metáforas, } \\
\text { Hegemonia, } \\
\text { Orientações: } \\
\text { econômicas, } \\
\text { políticas, } \\
\text { culturais, } \\
\text { ideológicas. }\end{array}$ & $\begin{array}{l}\text { Reprodução de linguagem (HQ) que } \\
\text { promove identidade. } \\
\text { Por outro lado, há uma ficcionalização } \\
\text { ainda maior no formato, que reduz o } \\
\text { problema na dinâmica da história em } \\
\text { quadrinhos, portanto, fantasia. }\end{array}$ & $\begin{array}{l}\text { Código que transmite um sentido de } \\
\text { verdade e de justiça. }\end{array}$ \\
\hline
\end{tabular}

Ao incorporar outras plataformas para promover a circulação do conteúdo da telenovela, a emissora se apoia na estratégia de transmídia, expandindo possibilidade de audiência e/ou reforçando a existente. Há um reaproveitamento estético e informacional na lógica das dimensões de texto e de produção discursiva, e uma ampliação da dimensão da prática social produzida por esses conteúdos "reempacotados", como indicado por Fechine et al (2013).

A dimensão da prática social da telenovela está situada na escolha de determinados temas que, com base numa perspectiva crítica, significa oferecer verdade ou restrição, leis mais críveis que aquelas indicadas pelo próprio legislativo. Ao dar luz e voz ao tema de interesse público, a novela assume um caráter de verdade, lapidando o tráfico de pessoas como algo real dentro de um espectro ficcional. O que sobra na dualidade entre o real e o ficcional se dá na relevância e na pertinência do tema, que é fato, gira recursos e interesses econômicos e políticos. É um tema capaz de ativar uma rede de comunicação pública ou não, agendando a pauta midiática. Portanto, a relação da ficção com a realidade está mais para a complementaridade que para uma diluição. 
Os índices de veracidade podem, paradoxalmente, estar mais associados à ficção do que as políticas públicas estabelecidas pelo Governo Federal, pois a novela dá cara e corpo à traficada. O governo orbita em leis, planos e programas de enfrentamento, que são impostos e estabelecidos, são unilaterais. A novela é mais relacional, traz outros elementos de interlocução via portal, programas de entretenimento, ou pelos demais produtos televisivos, além de uma série de informações na página de Salve Jorge, com dossiês e histórias em quadrinhos, porém, num espaço de tempo estabelecido, sendo que o crime é contínuo.

\section{Considerações finais}

A televisão ainda é um instrumento de narrar a história, a sociedade e tem a capacidade de influenciar o modo de pensar do público, principalmente por meio da telenovela, que é considerada um fenômeno cultural na América Latina. A telenovela, como gênero popular, cria um espaço público para compartilhar experiências e discussões da nação (Lopes, 2009) e as representações nas telenovelas tendem a traçar um paralelo entre as realidades políticas e sociais. Salve Jorge o fez. Ao dar voz e rosto a uma história e ao inserir no cotidiano do telespectador identidades sexuais estigmatizadas ou personagens em situações de violência (neste caso, o fato de trazer à tona $\mathrm{o}$ tema tráfico de pessoas), a telenovela afirma seu papel de narrativa capaz de refletir dramas privados que, ao ganharem visibilidade no espaço público se remetem não a um único indivíduo, mas a um coletivo que se posiciona em relação à experiência mediada do outro, produzindo uma percepção de realidade.

Porém, essa percepção de realidade é reduzida, suavizada. Em Salve Jorge, não há uma similaridade visual da traficada Ana Furtado com a personagem Morena (Nanda Costa). A lógica da cartilha das pesquisas da vida real não condiz com a estética do romance apresentado na telenovela.

Especificamente, nos produtos digitais derivados da novela tem-se um discurso híbrido, pois apresenta como fonte principal a própria trama do produto (Salve Jorge) e uma possível mescla de sons, tratamento de imagens e amplitude de abordagens em outros produtos midiáticos. Desse modo, há a presença de um discurso heterogêneo, sendo possível localizar o debate do tráfico de pessoas como um possível espaço de transformação social.

O merchandising social em telenovelas é eficaz na promoção e na visibilidade do tema que o próprio debate público, pois atinge o emocional, o lúdico e coloca o tráfico de pessoas na sala de sua audiência e repercute em outros produtos televisivos. Porém, Salve Jorge não oferece profundidade ao tema e utiliza distorções geográficas, visuais e relacionais que a ficção permite. Em contraponto à ideia de ficcionalidade surge, de forma efetiva, a inserção de fatos e elementos reais na ficção, reforçando o papel de aproximação com a veracidade social retratada.

$\mathrm{O}$ estudo reforçou a capacidade de que certas novelas têm de instaurar o debate público, indo além, sendo alvo do próprio debate, transformando um tema de interesse público em produto, traduzido em versões para além da telenovela, com base nos produtos transmidiáticos. Há um aproveitamento da trama em outros produtos de entretenimento, e a centralidade da mulher é reforçada em Salve Jorge e nas demais linguagens produzidas na $w e b$, correspondendo à lógica da realidade feminina como alvo e no combate ao crime. 


\section{Referências}

Alves, D. A. (2015). Interesse público e o poder da telenovela - merchandising social e repercussão do tráfico de pessoas em Salve Jorge. Tese de doutorado. Porto Alegre: Universidade Federal do Rio Grande do Sul (UFRGS).

Alves, D. A. (2017). Interesse público e entretenimento na dramatização do tráfico de pessoas em Salve Jorge. En Weber, M. H.; Coelho, M. y Locatelli, C. (orgs.). Comunicação Pública e Política - pesquisas e práticas (pp. 269-285). Florianópolis: Insular.

Baudrillard, J. (2014). A sociedade de consumo. $3^{\mathrm{a}}$ ed. São Paulo: Edições 70.

Bourdieu, P. (2012). A dominação masculina. Rio de Janeiro: Bertrand Brasil.

Brasil (2004). Decreto $n^{0} 5.017$, de 12/03/2004. Protocolo adicional à convenção das Nações Unidas contra o crime organizado transnacional relativo à prevenção, repressão e punição do tráfico de pessoas, em especial mulheres e crianças.

Brasil. Secretaria Nacional de Justiça (2008). Plano nacional de enfrentamento ao tráfico de pessoas. Secretaria Nacional de Justiça. Brasília: SNJ.

Brasil. Secretaria Nacional de Justiça (2013). II Plano nacional de enfrentamento ao tráfico de pessoas. Secretaria Nacional de Justiça. Brasília: Ministério da Justiça

Crenshaw, K. (2002). Documento para o encontro de especialistas em aspectos da discriminação racial relativos ao gênero. Estudos Feministas, 10(1), 171-188.

Fairclough, N. (2001). Discurso e mudança social. Brasília: Editora UNB.

Fechine, Y., Gouveia, D., Almeida, C., Costa, M. e Estevão, F. (2013). Como pensar os conteúdos transmídias na teledramaturgia brasileira? Uma proposta de abordagem a partir das telenovelas da Rede Globo. En Lopes, M. I. (Ed.), Estratégias de Transmidiação na Ficção Televisiva Brasileira (pp. 19-60). Porto Alegre: Sulina.

Foucault, M. (2002). A verdade e as formas jurídicas. Rio de Janeiro: Nau Editora.

G1, Globo (2013, 1 de fevereiro). Mulher que inspirou Morena de 'Salve Jorge' conta o drama no exterior. Entrevista. G1, Rio de Janeiro. Globo. Disponível em http://g1.globo. com/rio-de-janeiro/noticia/2013/02/mulher-que-inspirou-morena-de-salve-jorge-contao-drama-no-exterior.html

Gshow, Globo (2013, 22 de janeiro). O Drama de Jéssica: reveja a história da traficada em quadrinhos. Gshow. Disponível em http://gshow.globo.com/novelas/salve-jorge/ Fique-por-dentro/noticia/2013/01/o-drama-de-jessica-reveja-a-historia-da-traficada-emquadrinhos.html

Hamburger, E. (2005). O Brasil Antenado. A sociedade da Telenovela. Rio de Janeiro: Jorge Zahar. Jacks, N., Oikawa, E., Pereira Grijó, W., Avancini Alves, D., Reinhardt Piedras, E., Sgorla, R., Hastenpflug Wottrich, L., Sifuentes, L., Pereira Silva, L. A., Pieniz, M., Feitosa, S. A., Michela John, V. e Ronsini, V. (2013). Passione e Avenida Brasil: produção crossmídia e recepção transmidiática? En Lopes, M. I. (Ed.), Estratégias de Transmidiação na Ficção Televisiva Brasileira (p.p. 179-215). Porto Alegre: Sulina.

Leal, M. L. P. e Leal, M. F. P. (2002). Pesquisa sobre tráfico de mulheres, crianças e adolescentes para fins de exploração sexual comercial - PESTRAF: Relatório Nacional - Brasil. Brasília: CECRIA.

Lopes, M. I. V. (2003). Telenovela brasileira: uma narrativa sobre a nação. Comunicação e Educação, 26, 17-34.

Lopes, M. I. V. (2009). A telenovela como recurso comunicativo. MATRIZes, 3(1), 21-47.

Lopes, M. I. V. e Gomez Orozco, G. (2014). Síntese Comparativa dos Países do Obitel em 2013, En Lopes, M. I. V. e Gomez Orozco, G. (Eds.), Estratégias de produção transmídia na ficção televisiva: anuário Obitel 2014 (pp. 23-86). Porto Alegre: Sulina. 
Machado, A. (2001). Televisão levada a sério. São Paulo: Editora Senac.

Martín-Barbero, J. (2003). Dos meios às mediações: comunicação, cultura e hegemonia. Rio de Janeiro: UFRJ.

Vale, O. C. (2016). Metacontingências na novela Salve Jorge: A mídia televisiva no enfrentamento do tráfico de pessoas. Dissertação de Mestrado. Instituto de Psicologia, Universidade de Brasília (UnB).

Weber, M. H. (2000). Comunicação e espetáculos da política. Porto Alegre: Editora da Universidade, UFRGS.

Weber, M. H. e Souza, C. J. (2009). Dramatizações da Política na Telenovela Brasileira. Em Gomes, I. M. M. (Ed.), Televisão e Realidade (pp. 141-172). Salvador: Edufba. 